\title{
A Valuation Model for Callable Eurobonds
}

\author{
Vince Hooper ${ }^{1}$, John Pointon ${ }^{2}$ \\ ${ }^{1}$ School of Economics and Management, Xiamen University Malaysia, Kuala Lumpur, Malaysia \\ ${ }^{2}$ University of Plymouth, Plymouth, UK \\ Email: hoovcomm@hotmail.com
}

How to cite this paper: Hooper, V. and Pointon, J. (2019) A Valuation Model for Callable Eurobonds. Journal of Mathematical Finance, 9, 394-401. https://doi.org/10.4236/jmf.2019.93023

Received: February 1, 2019

Accepted: August 18, 2019

Published: August 21, 2019

Copyright $\odot 2019$ by author(s) and Scientific Research Publishing Inc. This work is licensed under the Creative Commons Attribution International License (CC BY 4.0).

http://creativecommons.org/licenses/by/4.0/

\begin{abstract}
This paper models the value of callable Eurobonds, using stochastic calculus, by assuming that the exchange rate follows a geometric Brownian motion process and the arrival time of an early redemption of the bond by the issuer conforms to a negative exponential distribution. The solution to the stochastic model shows that there is a relationship between the call premium and the expected time to the call which is consistent with traditional Black-Scholes pricing formulae. The magnitude of the call premium can be viewed as a signal to the market on a Government treasury's or company's expectations about the future level of interest rates and possible refinancing strategies. This paper is unique because as of July 2019 there exists no attempt at valuing Callable Eurobonds in the research literature.
\end{abstract}

\section{Keywords}

Stochastic Calculus, Callable Eurobonds, Term to Maturity, Poisson

Distribution, Negative Exponential, Geometric Brownian Motion, Call

Feature, Refinancing Strategy

\section{Introduction}

The purpose of this paper is to develop a valuation framework for callable Eurobonds. Whilst the most popular valuation model for options on stock has been centred around the Black-Scholes [1] option pricing model and has been developed in papers by Brennan and Schwartz (1977) [2], Ananthanarayanan and Schwartz (1980) [3], Jamshidian and Zhu (1988) [4], Athanassakos (1996) [5] and Brennan and Schwartz (1983) [6], they have not been extended to value bonds with embedded options such as callable Eurobonds, where there is foreign exchange risk. The models commonly used to value bonds with embedded options are subject to the criticisms of the general one-factor options-based models of bond prices. All the empirical research that has been conducted on Euro- 
bonds, conveniently excludes callable bonds from their samples thus further avoiding valuation issues.

Although these models form the basis for calculating the price of the issuer's "embedded" option by assuming that the issuer follows an "optimal" call policy by calling the bonds when the call price equals the market price, they are deficient because the term to maturity is an unknown parameter and is dependent upon a number of other variables. We develop a stochastic model for which the exchange rate follows a geometric Brownian motion process and the arrival time of the call by the company conforms to negative exponential distribution. The latter is equivalent to the probability of an arrival, within a given time interval, being Poisson distributed. The outcome of the model suggests that there is a relationship between the call price of the bond and the expected time to the call, at the time of issue (i.e. consistent with Black-Scholes [1]). This finding has important policy implications since the magnitude of the call value of the bond signals to the market on the probable call date and therefore has implications about an issuer's future refinancing strategy.

When callable bonds are issued there are provisions in the bond agreement for the possibility that the issuer can buy back or redeem the bond at some time in the future, at a premium above the face value of the bond known as the call premium, usually after a predetermined date. Effectively, the issuer has a call option on the bond. Essentially, the investors have obligations to redeem the bond if the firm chooses to do so. Since the company has a call option on the recall of the bonds they often tend to pay a higher coupon than non-callable bonds, or would issue the bond at a discount. There are potential problems associated with applying the Black-Scholes option pricing formula clones to pricing embedded options.

Callable bonds with a higher expected term to redemption have higher a call premium provision in the bond agreement than callable bonds with a lower expected term to redemption (refer to the Equations (20) and (21)). Seminal papers on bond call behavior suggest that a bond will be called in by the issuer when the market price of the bond is equal to the call value. However, recent theoretical and empirical findings on bond call behavior do not support bonds being redeemed when the call value equals the market price.

Recent development in the literature on bonds has incorporated other factors which influence when a call event may take place, other than interest rates. Longstaff and Tuckman (1993) [7] show that some firms may delay calling in the bonds early because of capital structure considerations and when there is more than one bond issue outstanding. Repurchase transactions are also viewed as a delay to calling in the bonds early [8]. Chaing and Narayanan (1991) [9] develop a methodology which implies that often bonds may be called when the bond price is less than its call price due to the effects of market imperfections, such as corporate taxes. Suboptimal calls in the Eurobond market is also supported by Bradley (1990) [10] who says that "sub optimal" behaviour has not been priced by researchers despite its prevalence. Information asymmetric effects have also 
been ignored [11]. In addition, a Eurobond issue may be associated with a Sinking Fund provision which requires the issuer to regularly redeem a fixed portion or all of the bonds with regard to a fixed schedule or through a third party trustee in an open market purchase. This was recently the case of Zambian government where the establishment of a contingency fund will see the country avoid defaulting when the loans are due for servicing starting 2021 until 2027 [12], through early redemption. Also, extraordinary redemption of Eurobonds can occur where an issuer calls bonds early if certain events occur such as a project which the bond was issued to finance is destroyed, damaged or becomes obsolete. Currency devaluation, due to a weak economy may also be a concern in terms of early redemption of callable bonds as in the case of Nigerian Sovereign callable Eurobonds. [13]. Also, many African banks have opted for early redemption of callable bonds citing the need to improve liquidity and capital structure.

The stochastic model developed in this paper incorporates the impact of transaction costs; capital structure; agency costs; and signalling, by implicitly embedding these factors by assuming that these cause bond call events to be randomly distributed across time. A useful distribution to model events which are random is the Poisson distribution. In the next section, the development of the Eurobond valuation model is outlined.

\section{Development of the Eurobond Valuation Model}

Assume a British Company/Government issuing Eurobonds in the US (in dollars).

Valuation is from the holder of the bonds perspective (i.e. investor).

The following notation will be used:

$B=$ par value of bond in dollars,

$r=$ dollar nominal interest rate,

$V=$ value of the bond, in sterling (GBP),

$t=$ time,

$T \equiv 1 / \lambda=$ mean time, in years, to the call for redemption by the company,

$k=$ annual UK market rate, continuously compounded,

$c=$ call premium,

$x=$ spot exchange rate: sterling for dollars,

$g=$ expected annual compound growth rate in the exchange rate, and

$\sigma=$ the standard deviation parameter.

The assumption about economic events following a Poisson distribution is supported in the literature in papers such as Miller and Weller (1990) [14] where the ending of speculative economic "bubbles" have been modeled using a Poisson process. Svenson (1991) [15] assumes that exchange rate devaluation events follow a Poisson distribution. In particular, the Poisson distribution assumes that in any positive time interval there is a positive probability of an arrival; that a maximum of only one arrival can occur in a sufficiently small interval of time; that the time intervals between adjacent arrivals are independently and identi- 
cally distributed; and that the probability of an arrival occurring in a time interval depends only on the length of the time interval and not upon the moment in time itself [16]. We assume that the call date events for Eurobonds are distributed as a Poisson process, across time. Therefore, this model is based upon the assumption that the probability that the bond will be redeemed during period $\mathrm{d} t$ is $\lambda d t$, and is Poisson distributed. Also, it is assumed that the exchange rate follows a geometric Brownian motion process which is supported strongly in recent Value at Risk forecasting research by Karim and Jaffar (2018) [17]:

$$
\mathrm{d} x=g x \mathrm{~d} t+\sigma x \mathrm{~d} z
$$

where,

$$
\mathrm{d} z=n(\mathrm{~d} t)^{1 / 2}
$$

where $n$ is the standard normally distributed variable.

Justification for incorporating a geometric Brownian motion process to model the exchange rate is supported by the derivation of the Black and Scholes (1973) [1] option pricing model and Brennan and Schwartz (1977) [2]. In the modeling of stochastic processes in economics and finance, asset prices are assumed, in general, to follow geometric Brownian motion processes [e.g. Cox and Huang (1989)] [18].

Now, the interest payment flow during $\mathrm{d} t$, in sterling, is Brxd $t$. If the bond is not redeemed, the end of period value, discounted to the beginning of the period, times the probability of no redemption during $\mathrm{d} t$ is:

$$
E(V+\mathrm{d} V)(1-\lambda \mathrm{d} t) /(1+k \mathrm{~d} t) .
$$

However, if the bond is redeemed, the end of period value in sterling, discounted to the beginning of the period, multiplied by the probability of redemption during $\mathrm{d} t$ is:

$$
B x(1+c) \lambda \mathrm{d} t /(1+k \mathrm{~d} t) .
$$

Therefore, it follows that the value of the bond in sterling is:

$$
V=B r x \mathrm{~d} t+E(V+\mathrm{d} V)(1-\lambda \mathrm{d} t) /(1+k \mathrm{~d} t)+B x(1+c) \lambda \mathrm{d} t /(1+k \mathrm{~d} t) .
$$

Now from Ito's lemma:

$$
E(\mathrm{~d} V)=\frac{\mathrm{d} V}{\mathrm{~d} x} g x \mathrm{~d} t+\frac{1}{2} \frac{\mathrm{d}^{2} V}{\mathrm{~d} x^{2}} \sigma^{2} x^{2} \mathrm{~d} t .
$$

Also, since $(\mathrm{d} t)^{2}$ rapidly tends to zero:

$$
1 /(1+k \mathrm{~d} t)=(1-k \mathrm{~d} t) /\left(1-k^{2}(\mathrm{~d} t)^{2}\right) \approx 1-k \mathrm{~d} t .
$$

and,

$$
\begin{gathered}
(1-\lambda \mathrm{d} t) /(1+k \mathrm{~d} t) \approx(1-\lambda \mathrm{d} t)(1-k \mathrm{~d} t) \approx(1-\lambda \mathrm{d} t-k \mathrm{~d} t) . \\
\lambda \mathrm{d} t /(1+k \mathrm{~d} t) \approx \lambda \mathrm{d} t(1-k d t) \approx \lambda \mathrm{d} t .
\end{gathered}
$$

Hence as $(\mathrm{d} t)^{2}$ tends to zero:

$$
V=B r x \mathrm{~d} t+(1-\lambda \mathrm{d} t-k \mathrm{~d} t)\left(V+\frac{\mathrm{d} V}{\mathrm{~d} x} g x \mathrm{~d} t+\frac{1}{2} \frac{\mathrm{d}^{2} V}{\mathrm{~d} x^{2}} \sigma^{2} x^{2} \mathrm{~d} t\right)+B x(1+c) \lambda \mathrm{d} t .
$$


and,

$$
\frac{1}{2} \frac{\mathrm{d}^{2} V}{\mathrm{~d} x^{2}} \sigma^{2} x^{2}+\frac{\mathrm{d} V}{\mathrm{~d} x} g x-(\lambda+k) V=-B x(r+(1+c) \lambda) .
$$

Now, the solution to an inhomogeneous second-order differential equation is given by adding any particular solution to the general solution of the associated homogeneous equation. So, if we set the right-hand side of Equation (8) equal to zero, the resultant general solution would be added to any solution to Equation (8). However, Dixit and Pindyck [19] (1994, page 181) demonstrate in problems of this type the general solution is just a speculative component of value. Hence, ignoring speculation, the solution is any particular solution. Given the linear function in $x$ on the right-hand side of Equation (8), and no constant, we can apply a linear trial function of the form:

$$
V=a x
$$

For constant $a$. Therefore, $\frac{\mathrm{d} V}{\mathrm{~d} x}=a, \frac{\mathrm{d}^{2} V}{\mathrm{~d} x^{2}}=0$, and so:

$$
0+\operatorname{agx}-(\lambda+k) a x=-B x(r+(1+c) \lambda) \text {. }
$$

Therefore,

$$
a=\frac{B(r+(1+c) \lambda)}{k+\lambda-g} .
$$

But $V=a x$, therefore the initial value of the bond is given by:

$$
V_{0}=\frac{B x(r+(1+c) \lambda)}{k+\lambda-g} .
$$

Let us now extend the model to take into account the situation in which the bond cannot be redeemed for the first $N$ years. The spot exchange rate is expected to be $x \mathrm{e}^{g N}$ in $N$ years' time. Hence, the expected value of the bond at the first point in time when the bond is first callable is given by:

$$
V_{c}=\frac{B x \mathrm{e}^{g N}(r+(1+c) \lambda)}{k+\lambda-g} \text {. }
$$

Now, the initial value of the bond in sterling, denoted by $U$, depends upon the discounted value of the interest flow for $N$ years plus the discounted value of the bond when first callable. Therefore, in continuous time:

$$
U=\int_{0}^{N} B r x \mathrm{e}^{g t} \mathrm{e}^{-k t} \mathrm{~d} t+V_{c} \mathrm{e}^{-k N}
$$

Therefore,

$$
U=B r x\left[\frac{\mathrm{e}^{-(k-g) t}}{-(k-g)}\right]_{0}^{N}+V_{c} \mathrm{e}^{-k N}
$$

and,

$$
U=B x\left[\frac{r}{k-g}-\frac{1}{\mathrm{e}^{(k-g) N}}\left(\frac{r}{k-g}-\frac{r+(1+c) \lambda}{k+\lambda-g}\right)\right]
$$


If the bond is issued at a discount of $D$ per cent $(U=B(1-D))$ :

$$
1-D=\frac{x r}{k-g}-\frac{x r}{\mathrm{e}^{(k-g) N}(k-g)}+\frac{x(r+(1+c) \lambda)}{\mathrm{e}^{(k-g) N}(k+\lambda-g)}
$$

Let

$$
w \equiv 1-D-x r /(k-g)+x r \mathrm{e}^{-(k-g) N} /(k-g)
$$

Therefore,

$$
\frac{x(r+(1+c) \lambda)}{\mathrm{e}^{(k-g) N}(k+\lambda-g)}=w
$$

Hence the required call premium is:

$$
c=\left[\left(w \mathrm{e}^{(k-g) N}(k+\lambda-g) / x\right)-r\right] / \lambda-1
$$

Alternatively, for a given call premium, we can determine the expected time to redemption $(N+T)$ by rearranging Equation (19):

$$
N+T \equiv N+\frac{1}{\lambda}=N+\left[\frac{x(1+c)-w \mathrm{e}^{(k-g) N}}{w \mathrm{e}^{(k-g) N}(k-g)-x r}\right]
$$

Holding all other variables constant, Equations (20) \& (21) show that the expected time to the maturity of the call is proportional to the magnitude of the call premium. Therefore, it may be inferred that the issuer of a callable foreign bond may be aware of the likely call date and builds these expectations into designing an issuing strategy by setting any discount or premium on issue and the value of the call (this is consistent with Black Scholes).

\section{Example}

From Equation (16). If:

The initial spot rate is GBP $0.83 / \$$, US nominal interest rates $1 \%$, UK nominal interest rates are $2 \%$, the bond cannot be redeemed for an initial 3 years, thereafter within a 10 year period the bond is expected to be called by the investor, for a variety of issues. The Face Value of the bond is $\$ 100$ which has a 20 year maturity and attracts a $10 \%$ premium on redemption. There is a $1 \%$ trend in the exchange rate per annum.

The initial value (fair value) of the bond in GBP Sterling

$$
\begin{aligned}
& =100 \times 0.83\left[\frac{0.01}{0.02-0.01}-\frac{1}{\mathrm{e}^{(0.02-0.01) \times 3}}\left(\frac{0.01}{0.02-0.01}-\frac{0.01+1.1 \times 0.1}{0.02+0.1-0.01}\right)\right] \\
& =90.3 \mathrm{GBP}
\end{aligned}
$$

Within the context of this example it is likely the bond will be issued in sterling at a much lower price to attract investors.

\section{Conclusion}

In this paper, the value of a foreign bond has been calculated by solving a sto- 
chastic equation which incorporates an exchange rate which follows a geometric Brownian motion process, and the arrival of the call by the issuer which follows a Poisson distribution. The model provides a simple solution to a problem where there are many stochastic parameters at work, and which have not been modelled by anyone successfully to date. The valuation formula predicts a direct relationship between the magnitude of the call value of the bond and the expected term to maturity. Thus the implications of this model are that bond issuers send signals to the market on their future refinancing strategies by setting the call premium, face value of the bond and any discounts or premia on the initial bond issue. Further empirical research may help to identify whether there is a relationship between the initial bond issue and future refinancing strategies of callable bond issues. This paper is unique because as of July 2019 there exists no attempt at valuing Callable Eurobonds in the research literature.

\section{Conflicts of Interest}

The authors declare no conflicts of interest regarding the publication of this paper.

\section{References}

[1] Black, F. and Scholes, M. (1973) The Pricing of Options and Corporate Liabilities. Journal of Political Economy, 81, 637-659. https://doi.org/10.1086/260062

[2] Brennan, M. and Schwartz, E. (1977) Savings Bonds, Retractable Bonds and Callable Bonds. Journal of Financial Economics, 5, 67-88. https://doi.org/10.1016/0304-405X(77)90030-7

[3] Ananthanarayanan, A.L. and Schwartz, E. (1980) Retractable and Extendible Bonds: The Canadian Experience. Journal of Finance, 35, 31-47. https://doi.org/10.1111/j.1540-6261.1980.tb03469.x

[4] Jamishidian, F. and Zhu, Y. (1988) Analysis of Bonds with Embedded Options. Advances in Futures and Options Research, 3, 63-95.

[5] Athanassakos, G. (1996) On the Application of the Black and Scholes Formula to Valuing Bonds with Embedded Options: The Case of Extendible Bonds. Applied Financial Economics, 6, 37-48. https://doi.org/10.1080/096031096334457

[6] Brennan, M. and Schwartz, E. (1983) Alternative Methods for Valuing Debt Options. Finance, 4, 119-137.

[7] Longstaff, F.A. and Tuckman, B. (1993) Optimal Call Policy for Corporate Bond. New York University, Salomon Brothers Working Paper S9355, New York.

[8] Mauer, D.C. (1993) Optimal Bond Call Policies under Transaction Costs. Journal of Financial Research, 161, 23-37. https://doi.org/10.1111/j.1475-6803.1993.tb00124.x

[9] Chaing, R.C. and Narayanan, M.P. (1991) Bond Refunding in Efficient Markets: A Dynamic Analysis with Tax Effects. Journal of Financial Research, 144, 287-302. https://doi.org/10.1111/j.1475-6803.1991.tb00667.x

[10] Bradley, F. (1990)) An Analysis of Call Strategy in the Eurodollar Bond Market. Journal of Financial Management and Accounting, 2, 23-46. https://doi.org/10.1111/j.1467-646X.1990.tb00016.x

[11] Ling, D.C. (1991) Optimal Refunding Strategies, Transaction Costs and the Market Value of Corporate Debt. Financial Review, 264, 479-500. 
https://doi.org/10.1111/j.1540-6288.1991.tb00392.x

[12] Frey, A. (2019) Zambia Sets Up Sinking Fund to Avoid Eurobond Default. Club of Mozambique.

https://clubofmozambique.com/news/zambia-sets-up-sinking-fund-to-avoid-eurob ond-default

[13] Onu, E. (2018) Sputtering Oil Industry Puts Brakes on Nigerian Bank Loans. Bloomberg.

https://www.bloomberg.com/news/articles/2018-12-11/sputtering-oil-industry-puts -brakes-on-lending-by-nigerian-banks

[14] Miller, M.H. and Weller, P. (1990) Currency Bubbles Which Affect Fundamentals: A Qualitative Treatment. Economic Journal, 100, 170-179. https://doi.org/10.2307/2234194

[15] Svenson, L.E.O. (1991) The Simplest Test of Target Zone Credibility. Centre for Economic Policy Research, Discussion Paper 493, London. https://doi.org/10.3386/w3394

[16] Wagner, H.M. (1975) Principles of Operations Research: With Applications to Managerial Decisions. Prentice-Hall, London.

[17] Karim, S.N. and Jaffar, M.J. (2018)) Forecasting Value at Risk of Foreign Exchange by Integrating Geometric Brownian Motion. International Conference on Soft Computing in Data Science, 15-16 August 2018, 186-198.

https://doi.org/10.1007/978-981-13-3441-2_15

[18] Cox, J.C. and Huang, C. (1989) Optimal Consumption and Portfolio Policies When Asset Prices Follow a Diffusion Process. Journal of Economic Theory, 491, 33-83. https://doi.org/10.1016/0022-0531(89)90067-7

[19] Dixit, A. and Pindyck, R. (1994) Investment under Uncertainty. Princeton University Press, Princeton. 